\title{
XVI. Observations on the late solar eclipse
}

\section{Thomas Squire Esq.}

To cite this article: Thomas Squire Esq. (1827) XVI. Observations on the late solar eclipse, Philosophical Magazine Series 2, 1:1, 55-55, DOI: 10.1080/14786442708674208

To link to this article: http://dx.doi.org/10.1080/14786442708674208

$$
\text { 曲 Published online: } 10 \text { Jul } 2009 .
$$

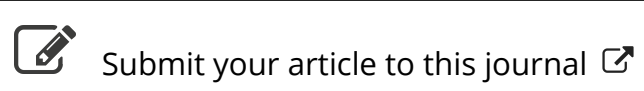

\footnotetext{
Llll Article views: 3
} 
XVI. Observations on the late Solar Eclipse. By Thomas SQuire, Esq.

To the Editors of the Philosophical Magazine and Annals.

Gentlemen,

THE day with us was rather unfavourable for observing the. late solar eclipse; I could not see the beginning, as the sun was obscured by clouds $(1-$ and $n-$ ) at the time. But at about two minutes after $10 \mathrm{M}$.S. T. the sun became visible through the passing nascent cumuli, when the obscuration was very considerable on the north-west part of the sun's disc. The eclipse continued to be visible at intervals till near the middle, when a dense cumulostratus again obscured the sun, but towards the end the air became clear, and continued so till the termination of the eclipse; and which took place here at $12^{\mathrm{h}} 0^{\mathrm{m}} 54^{\mathrm{s}}$ mean solar time. Latitude of the place $51^{\circ} 41^{\prime} 41^{\prime \prime} \cdot 6$ north. Longitude 27 seconds in time east of Greenwich. The above time reduced to that at the Royal Observatory gives $12^{\text {h }} 0^{\text {ta }} 27^{\mathrm{s}}$. Probably the end here was absolutely rather later than at Greenwich, owing to the effects of the lunar parallax, the moon being a little more depressed from our northern situation.

The above observations were made with one of Dollond's achromatic telescopes, and power of 80 . The time was de'duced from correct altitudes of the sun, taken with an excellent reflecting circle made by Troughton, having at the same time the latitude of the place and sun's declination given.

Epping, Dec, 15, 1826. I remain, Gentlemen, yours truly, Thomas Sguire.

XVII. On Fustic (Morus tinctorius), and its Application to the Dyeing of Yellow, Green, Olive, and Brown.' By E. S. GeorGe, Esq. F.L.S.*

THE wood of the Morus tinctorius is employed in dyeing 1 those shades of yellow in which intensity of colour is of more importance than brilliancy, and in all the range of colours formed by the mixture of yellow, blue, and red.

For those colours in which the sulphate of indigo is employed to give the blue, it is of great value, resisting the action of free sulphuric acid in a higher degree than any other yellow colouring matter.

* Communicated by the Author.

Having 